\title{
Influence of transition metals substitution on the superconductor $\mathrm{Bi}_{4} \mathrm{Ca}_{3} \mathrm{Sr}_{3} \mathrm{Cu}_{4} \mathrm{O}_{y}$
}

\author{
E V SAMPATHKUMARAN and R VIJAYARAGHAVAN \\ Tata Institute of Fundamental Research, Homi Bhabha Road, Bombay 400005. India \\ Abstract. The results of our investigation on the specimens $\mathrm{Bi}_{4} \mathrm{Ca}_{3} \mathrm{Sr}_{3} \mathrm{Cu}_{4-x} T_{x} \mathrm{O}_{y}(T=\mathrm{Fe}$, \\ $\mathrm{Co}, \mathrm{Ni}, x \leqslant 0.5)$ synthesized in air are presented. Fe and $\mathrm{Co}$ substituents result in the \\ formation of $\mathrm{Bi}_{2} \mathrm{Sr}_{2} \mathrm{CuO}_{y}$-type of phase, with considerable depression of $T_{c}$ of the main phase. \\ However, $\mathrm{Ni}$ is completely soluble with $\mathrm{Cu}$ in this concentration range without significant \\ depression of superconducting transition temperature $\left(T_{c}\right)$. This difference in the solubility \\ behaviour of $\mathrm{Fe}$ and $\mathrm{Co}$ on the one hand and $\mathrm{Ni}$ on the other is explained taking into account \\ ionic charge and coordination number mismatches.
}

Keywords. $\mathrm{Bi}_{4} \mathrm{Ca}_{3} \mathrm{Sr}_{3} \mathrm{Cu}_{4-x} T_{x} \mathrm{O}_{y}$; solubility behaviour; superconductivity.

\section{Introduction}

The investigation of chemical substitutional effects in high $T_{c}$ superconductors has contributed to the advancement of knowledge on these oxides. However, the results of such studies on the bismuth-based superconductor, $\mathrm{Bi}-\mathrm{Ca}-\mathrm{Sr}-\mathrm{Cu}-\mathrm{O}$ are in general quite complicated due to the fact that $T_{c}$ values differ significantly depending on the value of $n$ in $\mathrm{Bi}_{2} \mathrm{Sr}_{2} \mathrm{Ca}_{n-1} \mathrm{Cu}_{n} \mathrm{O}_{y}\left(n=1, T_{c}=10 \mathrm{~K} ; n=2, T_{c}=80 \mathrm{~K} ; n=3, T_{c}=110 \mathrm{~K}\right)$ as well as on the synthetic conditions (Maeda et al 1988; Tarascon et al 1988; Sheng and Herman 1988; Parkin et al 1988; Torardi et al 1988). It is, therefore, absolutely essential to keep the synthetic conditions the same for a meaningful comparison of the characteristics of several chemically-substituted bismuth-based superconductors. The results of such an investigation have been reported by us for some chemical substituents (Sampathkumaran et al 1988; Ikeda et al 1988). Here, we present the results of our investigation to substitute $\mathrm{Fe}, \mathrm{Co}$ and $\mathrm{Ni}$ for $\mathrm{Cu}$ in $\mathrm{Bi}_{4} \mathrm{Ca}_{3} \mathrm{Sr}_{3} \mathrm{Cu}_{4} \mathrm{O}_{y}$ (referred hereafter as 4334 phase).

\section{Experimental}

The samples, $\mathrm{Bi}_{4} \mathrm{Ca}_{3} \mathrm{Sr}_{3} \mathrm{Cu}_{4-x} T_{x} \mathrm{O}_{y}(T=\mathrm{Fe}, \mathrm{Co}, \mathrm{Ni} ; x \leqslant 0.5 ; y=$ undetermined $)$ were prepared in air under identical conditions as described earlier (Sampathkumaran et al 1988). X-ray powder diffraction patterns were recorded employing $\mathrm{CuK}_{\alpha}$ radiation. AC susceptibility $(\chi)$ and DC resistance $(R)$ were measured in the temperature range 12 $300 \mathrm{~K}$ in a closed cycle refrigerator (Sumitomo Industries, model SCR 204T). DC $\chi$ measurements $(4.2-300 \mathrm{~K})$ were performed on selected specimens in a field of about $4 \mathrm{kOe}$. It may be remarked that some results on nickel specimens have already been published earlier by us (Sampathkumaran et al 1988).

\section{Results and discussion}

The X-ray diffraction spectra are shown in figure 1 for selected concentrations. The diffraction patterns look similar for $x=0$ and the nickel specimens, which could be 


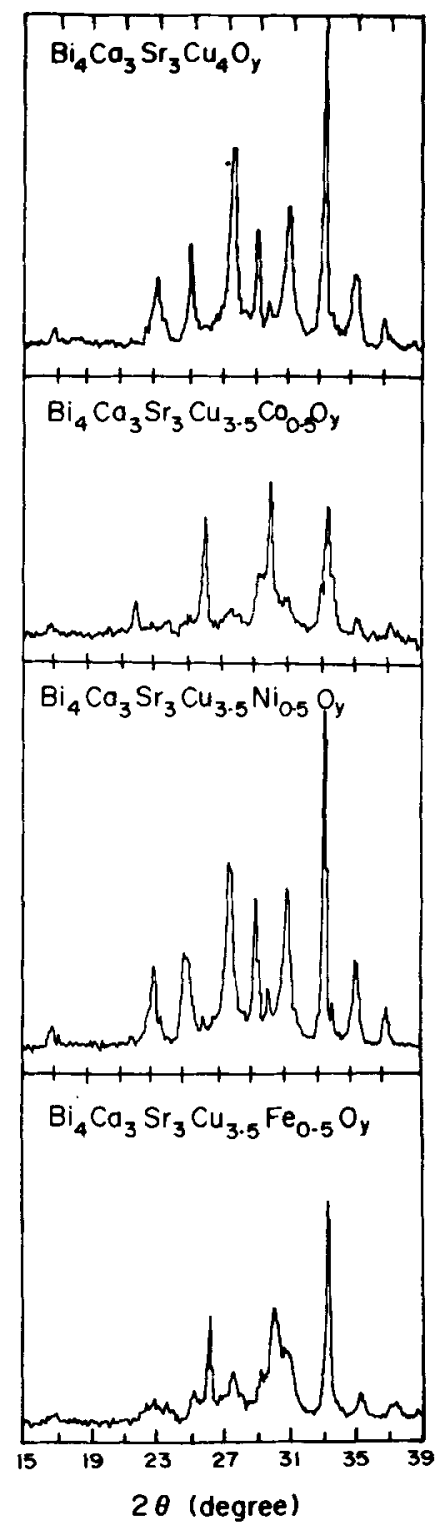

Figure 1. X-ray diffraction pattern $\left(\mathrm{CuK}_{\alpha}\right)$ of the specimens, $\mathrm{Bi}_{4} \mathrm{Ca}_{3} \mathrm{Sr}_{3} \mathrm{Cu}_{3.5} \mathrm{~T}_{0.5} \mathrm{O}_{y}$ $(T=\mathrm{Fe}, \mathrm{Co}, \mathrm{Ni}$ and $\mathrm{Cu})$.

indexed on the basis of $n=2$ phase. However, for Fe and Co specimens, additional lines appear in the X-ray pattern even for small concentrations $(x=0.1$ and not shown in figure), the intensity of which increases with $x$. These lines are dominant for $x=0.5$ (see figure 1) and could be indexed on the basis of $n=1$ phase. We have also investigated the diffraction pattern at the low angle region $\left(2 \theta=3^{\circ}\right.$ to $\left.8^{\circ}\right)$ and the position of $(002)$ line (not shown in figure) is consistent with these conclusions. Thus it appears that nickel could be easily substituted for $\mathrm{Cu}$ than $\mathrm{Fe}$ and $\mathrm{Co}$. While our work was nearing completion we came to know that Tarascon et al (1989a) could not substitute any of 


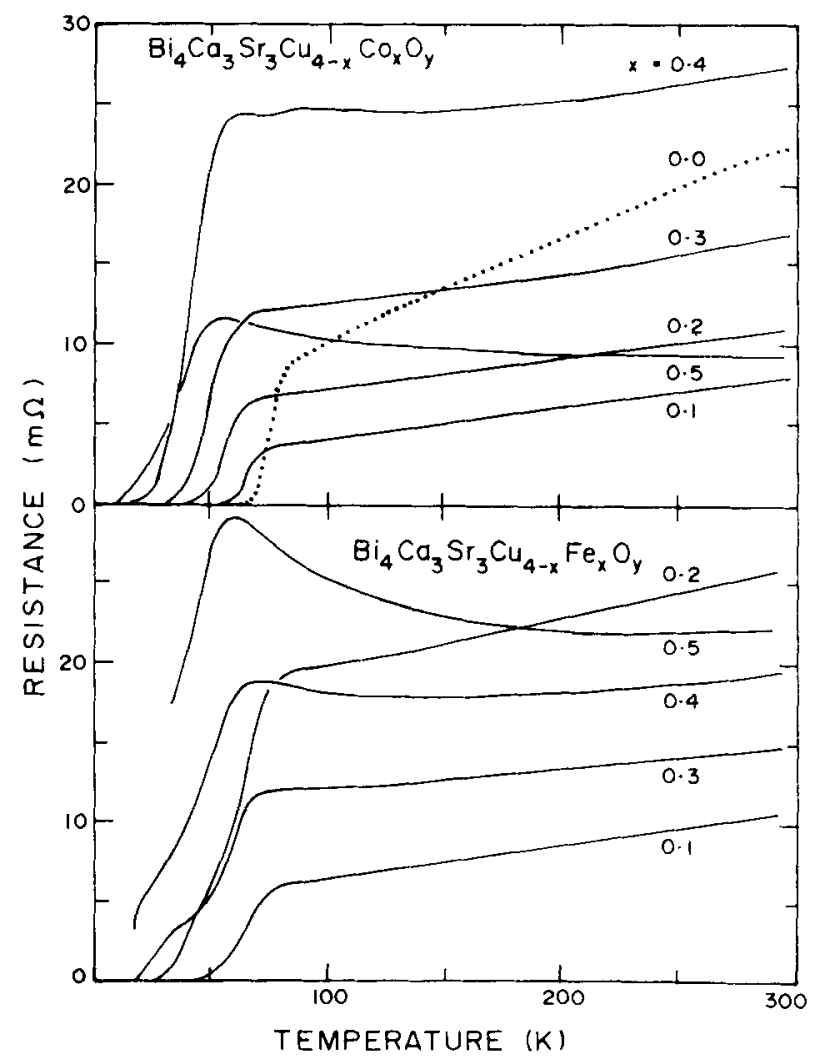

Figure 2. Resistance as a function of temperature for the specimens, $\mathrm{Bi}_{4} \mathrm{Ca}_{3} \mathrm{Sr}_{3} \mathrm{Cu}_{4-x} T_{x} \mathrm{O}_{y}(T=\mathrm{Fe}$ and $\mathrm{Co} ; x \leqslant 0.5)$.

these transition metal ions in $\mathrm{Bi}_{2} \mathrm{Sr}_{2} \mathrm{CaCu}_{2} \mathrm{O}_{y}$ for their synthetic conditions in air, whereas the same group (Tarascon et al 1989 b, c; Le Page et al 1989) reported the formation of $\mathrm{Bi}_{2} \mathrm{Sr}_{3} \mathrm{~T}_{2} \mathrm{O}_{y}(T=\mathrm{Fe}$ and $\mathrm{Co}$ ) with more stringent synthetic conditions. These results emphasize the role of heat-treatment conditions, and also possibly $\mathrm{Ca} / \mathrm{Sr}$ ratios in substitutional effects.

The results of $R$ and a.c. $\chi$ measurements on Fe and Co specimens are shown in figures 2 and 3. As remarked earlier (Sampathkumaran et al 1988), nickel substitution results in $T_{c}$ (onset) at about $80 \mathrm{~K}$ as in the case of $\mathrm{Bi}_{4} \mathrm{Ca}_{3} \mathrm{Sr}_{3} \mathrm{Cu}_{4} \mathrm{O}_{y}$ for all values of $x \leqslant 0.5$. However, Fe and Co substitution results in the gradual depression of $T_{c}$ as shown by $T_{c}$-onset (defined as the temperature at which $R$ starts decreasing drastically), as well as $T_{c}$ (the temperature at which $R=0$ and $\chi$ starts becoming negative). For $x$ $=0.5$ of $\mathrm{Fe}$ and Co series, superconductivity in the temperature range of investigation is not observable as inferred from a.c. $\chi$ measurements; the observed drop in $R$ may indicate the existence of small traces of superconducting phase. The systematic decrease of $T_{c}$ with $\chi$ indicates that certain fractions of $\mathrm{Fe}$ and $\mathrm{Co}$ ions do enter the lattice of (4334) phase, though the X-ray patterns showed the formation of $n=1$ phase with increasing $x$. It appears that the effect of Co dopant on $T_{c}$ is more drastic than that of $\mathrm{Fe}$, possibly due to the higher solubility limit of $\mathrm{Co}$ at the $\mathrm{Cu}$ site than of $\mathrm{Fe}$ under our synthetic conditions. 


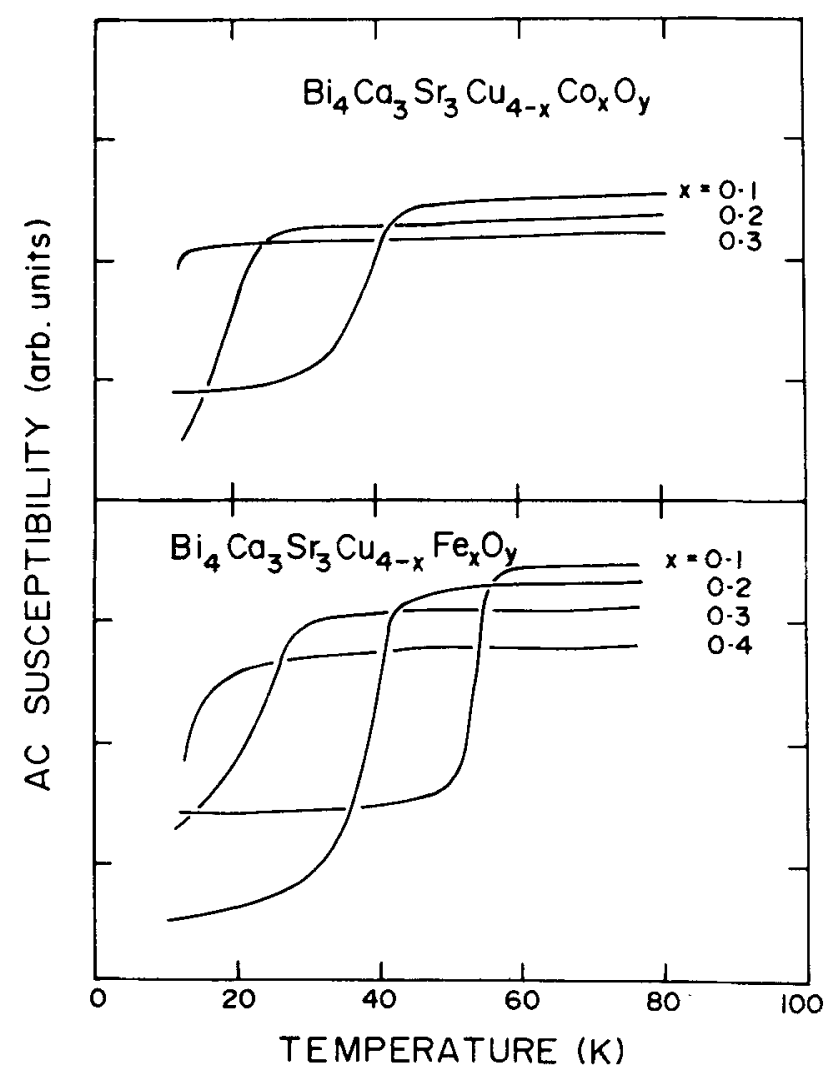

Figure 3. AC susceptibility as a function of temperature for the superconducting specimens, $\mathrm{Bi}_{4} \mathrm{Ca}_{3} \mathrm{Sr}_{3} \mathrm{Cu}_{4-x} T_{x} \mathrm{O}_{y}(T=\mathrm{Fe}$ and $\mathrm{Co}, x<0.5)$. For clarity, the base line (above $100 \mathrm{~K}$ ) for all $\chi$ is shifted.

We also performed d.c. susceptibility measurements on selected specimens, the results of which are shown in figure 4. We observe a Curie-Weiss behaviour of $\chi$ above $100 \mathrm{~K}$ for all specimens, with $\chi$ increasing as one goes from $\mathrm{Ni}$ to Co to Fe. A peak in the $\chi$ data around $50 \mathrm{~K}$ has been observed for $x=0.5$. Since $\mathrm{Ni}$ specimens are found to be superconducting around this temperature, the drop in $\chi$ below $50 \mathrm{~K}$ (not shown in the figure) may be due to the dominant diamagnetic contribution $\left\{\left(\chi^{-1}\right.\right.$ at $300 \mathrm{~K}$ $=900 \mathrm{~mole} / \mathrm{emu}$ and at $100 \mathrm{~K}=525 \mathrm{~mole} / \mathrm{emu})\}$. On the other hand, for $\mathrm{Fe}$ and $\mathrm{Co}$ specimens $(x=0.5)$, this peak may be associated with the antiferromagnetic ordering of transition metal ions in $n=1$ phase. In support of this, Tarascon et al (1989b) have reported antiferromagnetic ordering of $\mathrm{Bi}_{2} \mathrm{Sr}_{2} \mathrm{Cu}_{1-x} T_{x} \mathrm{O}_{y}(T=\mathrm{Fe}$ and $\mathrm{Co})$. The results of detailed $\mathrm{DC} \chi$ studies will be published elsewhere.

\section{Conclusion}

The results presented in this paper suggest that the attempts to substitute $\mathrm{Fe}$ and $\mathrm{Co}$ under our preparative conditions in the 4334 phase of the Bi-based superconductor 


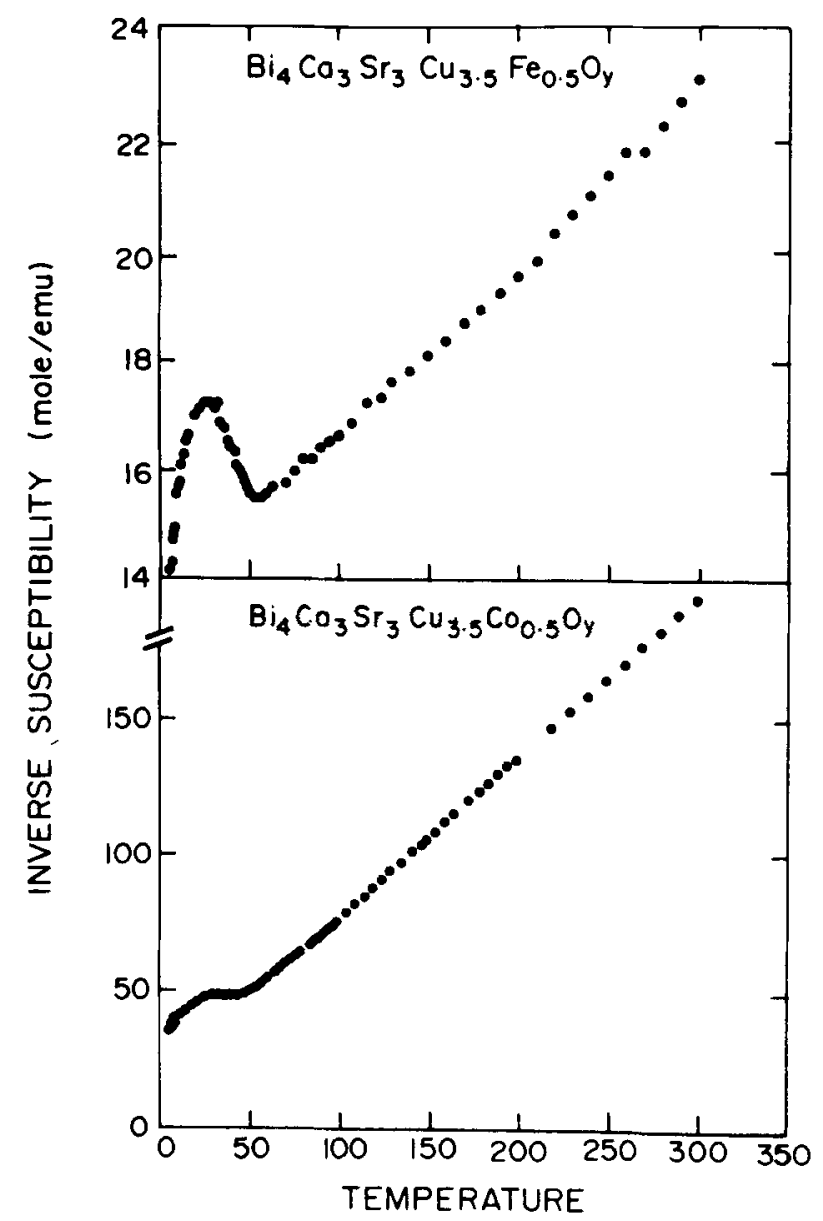

Figure 4. DC inverse susceptibility as a function of temperature $(4.2-300 \mathrm{~K})$ for the specimens, $\mathrm{Bi}_{4} \mathrm{Ca}_{3} \mathrm{Sr}_{3} \mathrm{Cu}_{4}{ }_{r} T_{x} \mathrm{O}_{v}(T=\mathrm{Fe}$ and $\mathrm{Co}$.

result in the formation of $n=1$ phase. However, Ni could be substituted for $\mathrm{Cu}$ without this extra phase. The difference in the substitutional behaviour of these $T$ ions may be associated with the valency, size and co-ordination number of mismatches with respect to $\mathrm{Cu}$. $\mathrm{Cu}$ is known to be five-fold co-ordinated in the $n=2$ phase, whereas it is six-fold co-ordinatated in the $n=1$ phase. It appears that $\mathrm{Fe}$ and Co prefer to be trivalent, preferring six-fold co-ordination (Tarascon et al 1989a). Therefore, these substituents favour in general $n=1$ phase under normal heat-treatment conditions. Presumably, Ni and $\mathrm{Cu}$ are nearly isovalent, thereby explaining solubility. These views are consistent with the observations noted for the solubility behaviour in $\mathrm{YBa}_{2} \mathrm{Cu}_{3} \mathrm{O}_{7}$ system by several groups. It is generally believed that $\mathrm{Co}$ does not occupy $\mathrm{Cu}$ in $\mathrm{CuO}_{2}$ planes (in which $\mathrm{Cu}$ is five-fold co-ordinated), but on the chains resulting in the addition of oxygen to make $\mathrm{Cu}$ six-fold co-ordinated. However, Ni substitution on the $\mathrm{CuO}_{2}$ plane in $\mathrm{YBa}_{2} \mathrm{Cu}_{3} \mathrm{O}_{7}$ is possible as noted by us in the bismuth system, due to the fact that $\mathrm{Cu}$ in $\mathrm{CuO}_{2}$ planes is five-fold co-ordinated. 


\section{Acknowledgements}

One of the authors (EVS) would like to thank Prof. K Kohn, Waseda University, for hospitality during his visit, and for his association in sample preparation.

\section{References}

Ikeda N, Kohn K, Sampathkumaran E V and Vijayaraghavan R 1988 Solid State Commun. 6851

Maeda H. Tanaka Y. Fukutumi M and Asano T, 1988 Jpn J. Appl. Phys. 27 L209

LePage Y, McKinnon W R, Tarascon J M and Barboux P 1989 (Preprint)

Parkin S S P, Lee V Y, Engler E M, Nazzal A I. Huang T C, Gorman G, Savoy R and Beyers R 1988 Phys. Ret. Lett. 602539

Sampathkumaran E V. Vijayaraghavan R, Ikeda N and Kohn K 1988 J. Phys. C18 L163

Sheng Z Z and Herman A 1988 Nature (London) 332138

Tarascon J M. Le Page Y, Barboux P. Bagley B G, Greene L H, McKinnon W R, Hull G W, Giroud M and Huang D M 1988 Phys. Rev. B37 9382

Tarascon J M, Barboux P, Hull G W, Ramesh R. Greene L H, Giroud M. Hegde M S and McKinnon W R 1989a Phys. Rev. B39 4316

Tarascon J M, Miceli P F, Barboux P. Hwang D M, Hull G W, Giroud M, Greene L H. LePage Y, McKinnon W R, Tselepis E, Pleizier G, Eibschutz M. Neumann D A and Rhyne J J 1989b Phys. Rev. B39 11587

Tarascon J M, Ramesh R, Barboux P, Hegde M S, Hull G W, LePage Y, McKinnon W R, Waszeak J V and Schneemeyer 1989c (Preprint)

Torardi C C, Subramanian M A, Calabrese J C, Gopalakrishnan J, Morissey K J, Askew T R, Flippen R B, Chaudry U and Sleight A W 1988 Phys. Rev. B38 225 